\title{
Die Buntdachblume (Leycesteria formosa), ein attraktiver Blüten- und Fruchtsolitär
}

\author{
Veit M. Dörken \& Annette Höggemeier
}

\begin{abstract}
The Himalayan Honeysuckle (Leycesteria formosana) from East-Asia is only rarely cultivated in central Europe which deserves more attention. It is an interesting solitary shrub with unusual inflorescences and fruit.
\end{abstract}

\section{Zusammenfassung}

Die Buntdachblume (Leycesteria formosana) ist eine in Mitteleuropa selten gepflanzte ostasiatische Strauchart mit einem ungewöhnlichen Blüten- und Fruchtschmuck. Die Art verdient mehr Beachtung, zumal sie sich hervorragend zur Solitärstellung in klimatisch geschützten Lagen eignet.

\section{Einleitung}

Unter den zahlreichen bei uns in Gärten kultivierten asiatischen Sträuchern sollte der bei uns bislang nur selten gepflanzten Buntdachblume (Leycesteria formosana) wegen ihres exotisch anmutenden Erscheinungsbildes mehr Beachtung geschenkt werden. Auffällig sind hier vor allem der eigentümlich wirkende Blütenflor sowie die Früchte. Die Gattung wurde zu Ehren des englischen Richters William Leycester (1775 - 1831) benannt, der sich in Vorderindien

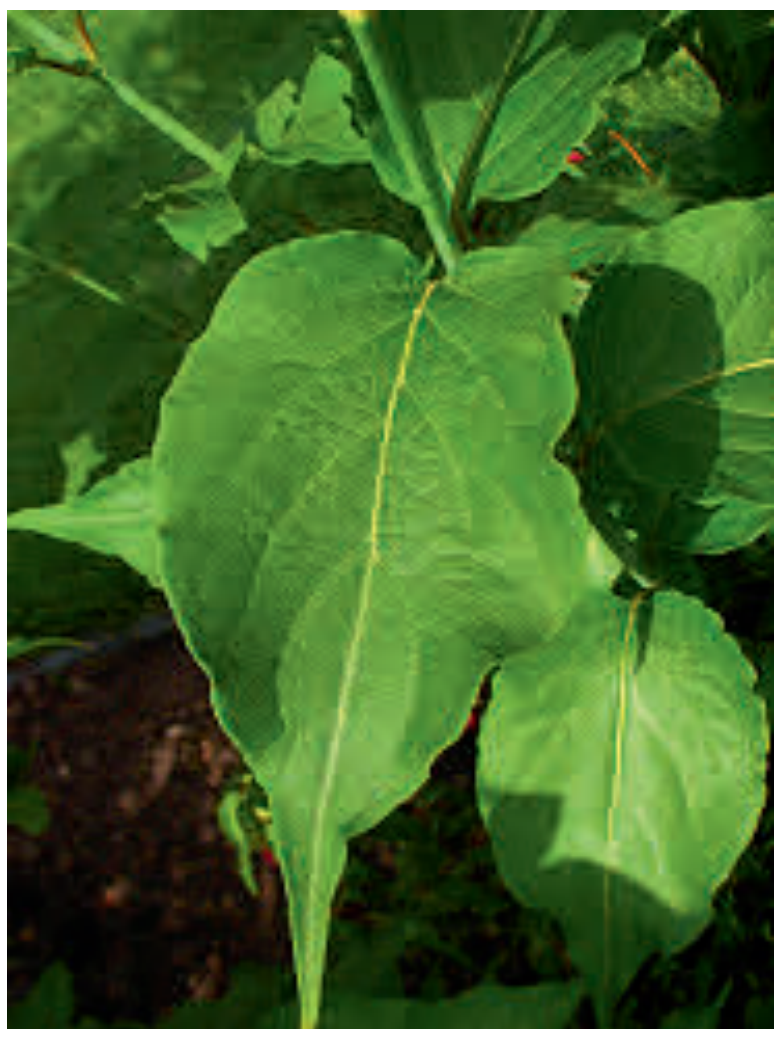

auch mit dem Sammeln von Pflanzen beschäftigte und daher in Indien als Förderer der Botanik gilt.

\section{Systematik und Verbreitung}

Buntdachblumen sind Geißblattgewächse (Caprifoliaceae). In diese Familie gehören auch viele unserer bekannten Ziersträucher wie z.B.

Abb. 1 (links): Blatt von Leycesteria formosa.

Abb. 2 (rechts): Stamm mit graubrauner Rinde.

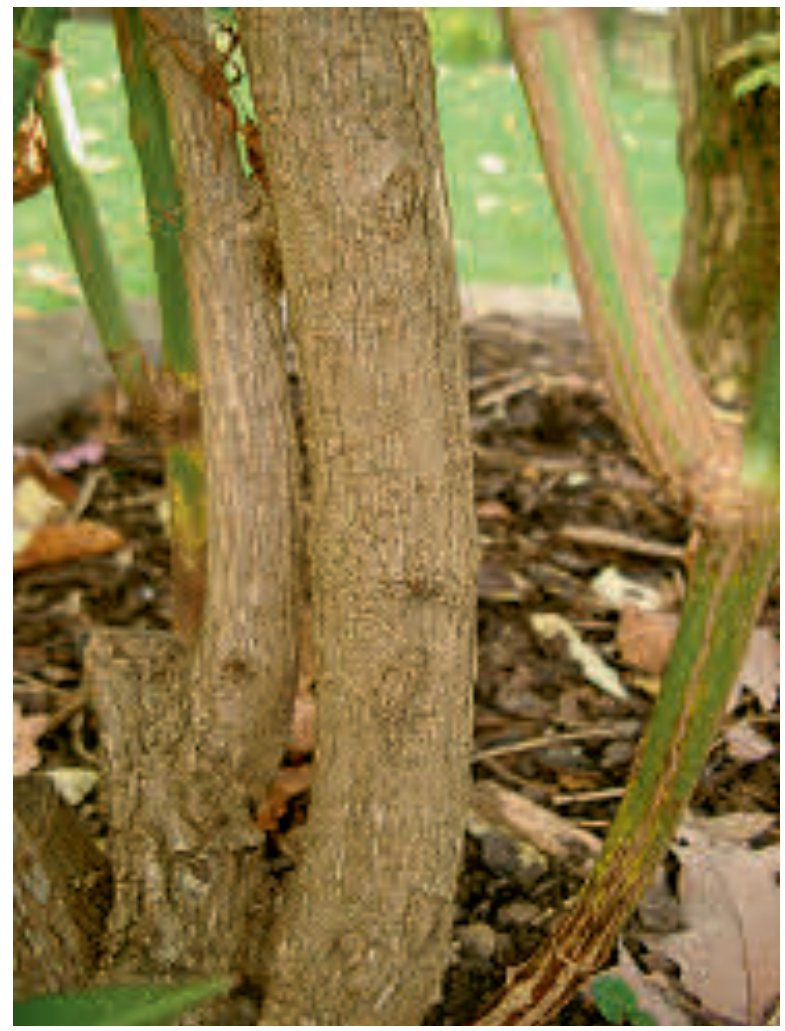




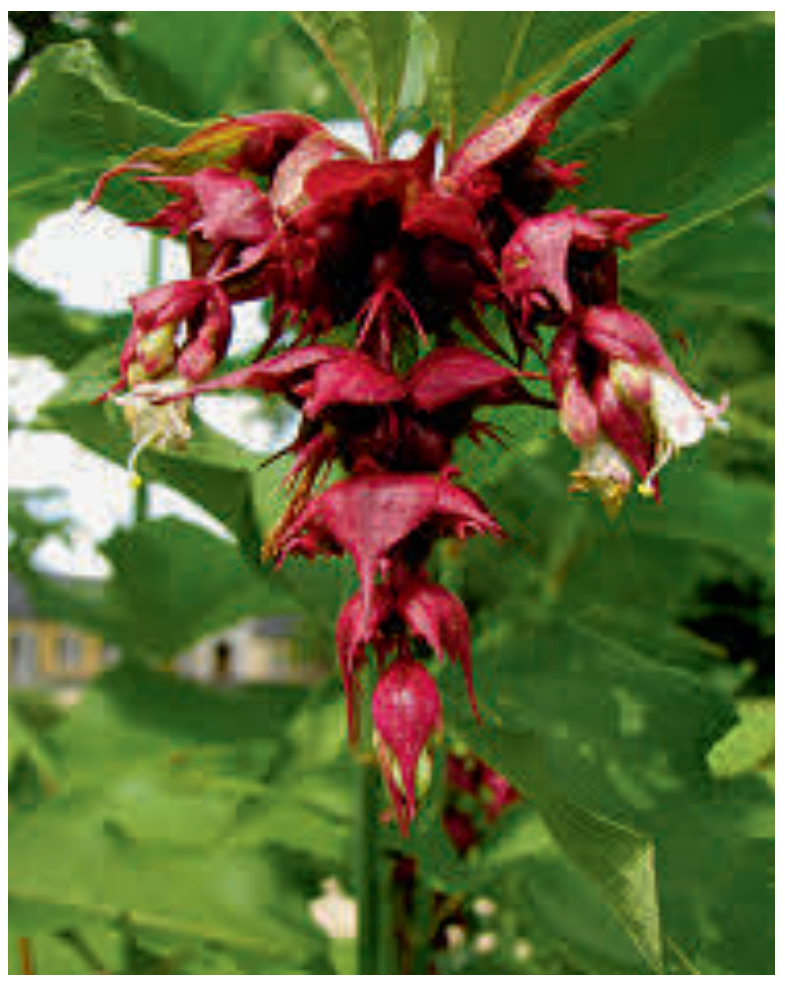

Geißblatt (Lonicera), Weigelie (Weigela) oder Schneebeere (Symphoricarpos). Die Gattung Leycesteria umfasst sechs Arten, die vom WHimalaya bis SW-China verbreitet sind (RoLOFF \& BÄrTels 1996). Da die Früchte häufig von Vögeln gefressen werden, die für die Ausbreitung sorgen, kann sich der Strauch in besonders milden Regionen Europas relativ schnell über weite Distanzen ausbreiten und als Neophyt Fuß fassen. In Deutschland geht von ihm vermutlich keine Gefahr als invasiver Neophyt aus. In Teilen Englands, auf Madeira und den Azoren gilt Leycesteria formosana als eingebürgert.

\section{Morphologie}

Der winterkahle Strauch wird maximal $3 \mathrm{~m}$ hoch. Seine hohlen, jungen Triebe sind zunächst bläulich bereift, später jedoch glänzend grün. Die breit-eiförmigen, im Austrieb leicht behaarten, bis $20 \mathrm{~cm}$ langen gegenständigen Blätter bilden eine lange ausgezogene Spitze. Der Blattrand ist glatt oder gelegentlich auch leicht gesägt. Die Blüten stehen in überhängenden, bis $15 \mathrm{~cm}$ langen Trauben in den Achseln dunkel purpurfarbener großer Deckblätter. Der deutsche Name bezieht sich auf die Deckblät-

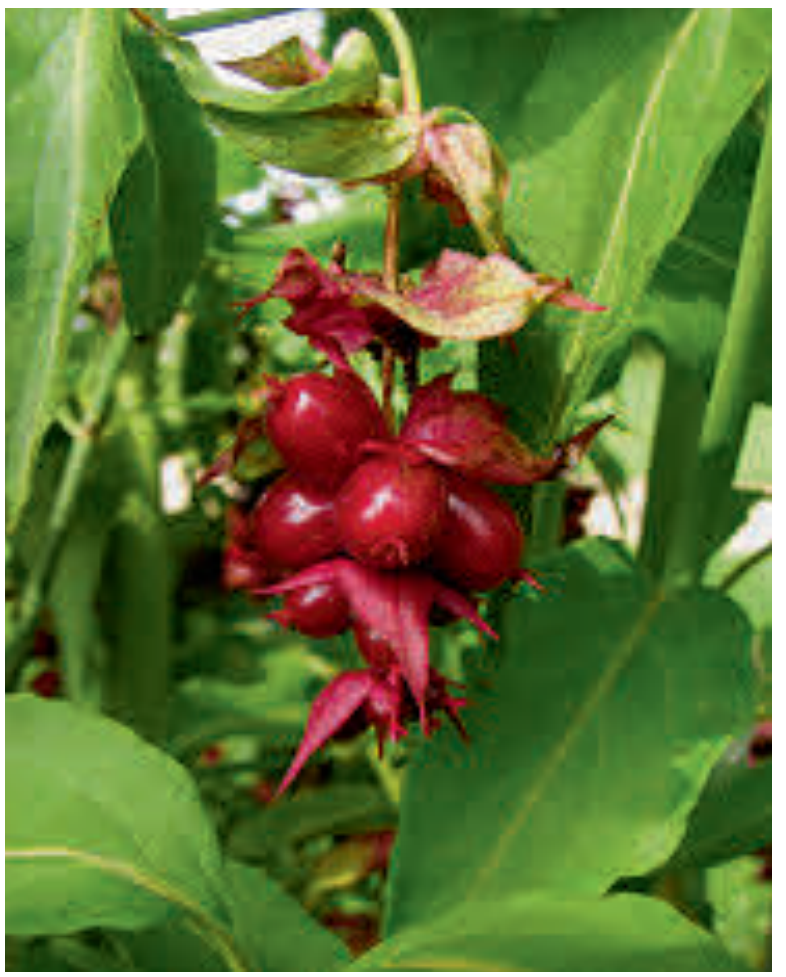

ter, die auffälliger als die Blüten sind und diese „überdachen“. Die Einzelblüten sind bis $2 \mathrm{~cm}$ lang und weißlich oder rosa bis purpurn gefärbt. Ihre Blütenhülle ist in Kelch- und Kronblätter gegliedert, die Kelchblattzipfel sind kleiner als die Kronblätter. Sowohl Kelch als auch die runden, vielsamigen roten Beerenfrüchte sind dicht drüsig bewimpert.

\section{Kulturansprüche und Verwendung}

Für ein möglichst gutes Gedeihen benötigt die relativ anspruchslose Buntdachblume einen geschützten Standort. Da die Triebe oft nicht rechtzeitig ausreifen, kann es zu Schäden durch starke Fröste kommen (Krüssmann 1976; Eiselt \& Schröder 1977). Im Botanischen Garten Bochum haben die dort gepflanzten Individuen auch die Extremwinter 2008/2009

Abb. 3 (links): Blütenstand von Leycesteria formosa. Abb. 4 (rechts): Fruchtende Leycesteria formosa.

Abb. 5 (Seite 35 oben): Leycesteria formosa; Tafel 120 aus „Plantae asiaticae rariores“, Vol. 2, 1830)

Abb. 6 (Seite 35 unten): Die jungen Triebe der Buntdachblume sind auffällig grün gefärbt. 
und 2009/2010 mit tagelangen Temperaturminima von $-20^{\circ} \mathrm{C}$ im Freiland überlebt. Dort sind sie zwar bis zum Boden zurückgefroren, aber dann im nächsten Frühjahr durch zahlreiche Schösslinge wieder kräftig durchgetrieben. Besonders bei Kahlfrösten empfiehlt es sich daher, den basalen Bereich z. B. mit Fichtenreisig zu schützen. Wenn ein Rückschnitt erforderlich ist, sollte dieser nach den letzten Frösten geschehen. Alte Individuen können aufgrund der sehr hohen Regenerationsfähigkeit problemlos im Frühjahr nach dem Frost über dem Boden heruntergeschnitten werden. Sie treiben dann wieder mit zahlreichen leuchtend frischgrünen Trieben aus. Nach dem Rückschnitt empfiehlt sich eine ausreichende Düngung sowie eine Mulchung mit Laubkompost (Kelly \& Hillier 2004). Die Buntdachblume verträgt fast alle Bodenarten, bevorzugt jedoch lockere, durchlässige Substrate. Besonders gut geeignet sind warme, frische, humose Substrate (KRÜsSMAnN 1976; Eiselt \& Schröder 1977). Sie toleriert Luftverschmutzungen in Industriegebieten sowie Salzluft in küstennahen Regionen (Kelly \& Hillier 2004). Deshalb ist es für sie kein Problem, als Neophyt z. B. auf den Azoren oder auf Madeira Hänge in Meeresnähe zu besiedeln. Außer durch Aussaat kann die Art auch problemlos über Stecklinge vermehrt werden (EISElt \& SCHRÖDER 1977).

Die Buntdachblume ist ein ausgesprochen attraktiver Strauch, der auch in mitteleuropäischen Gärten mehr Beachtung verdient. Ideal ist eine solitäre Stellung, damit die hübschen Blüten- und Fruchtstände besonders gut zur Geltung kommen. Im Palmengarten gedeiht Leycesteria im Asienbeet, das sich in der Nähe des Cafés Siesmayer befindet.

\section{Literatur}

EIselt, M. G. \& SChröder, R. 1977: Laubgehölze. Leipzig.

Kelly, J. \& Hillier, J. 2004: Bäume und Sträucher, 2. Aufl. - Braunschweig.

Krüssmann, G. 1976: Handbuch der Laubgehölze,

Band 2: - Berlin. Hamburg.

Roloff, A. \& Bärtels, A. 1996: Gartenflora,

Band 1: Gehölze. - Stuttgart.
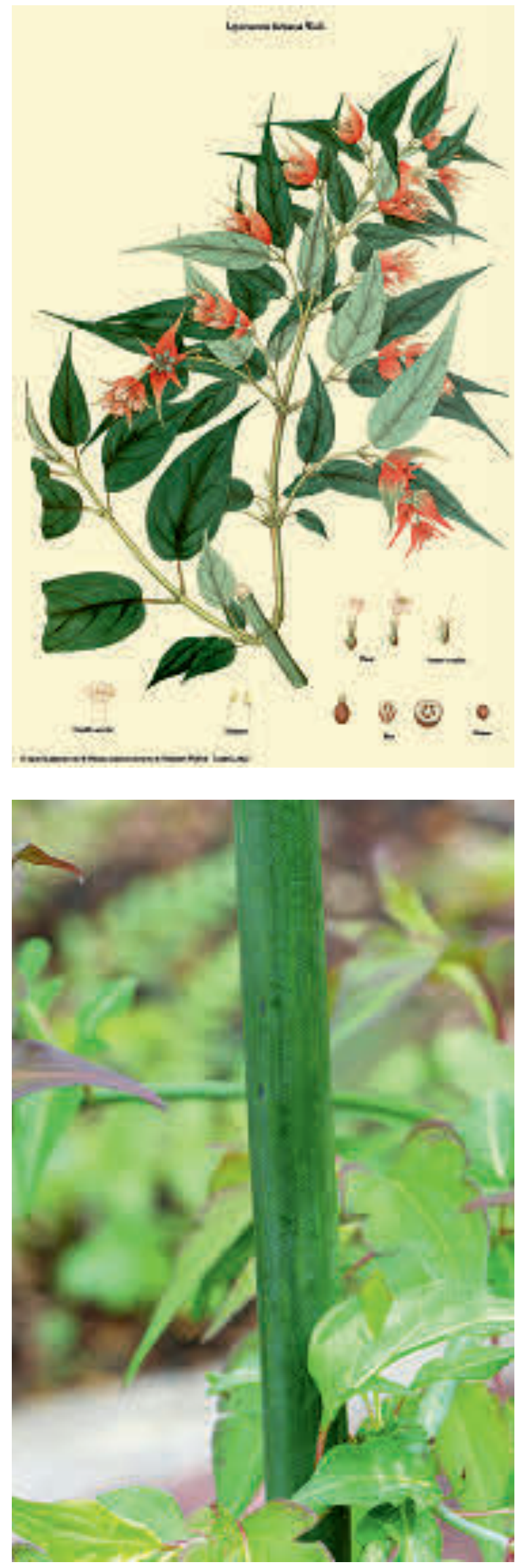